\title{
Preparation and Synergistic flame retardant effects of Iron Doped Lanthanum Stannate in PP/APP/PER System
}

\author{
Yun-hong Jiao ${ }^{* 1 a}$, Ling Shi ${ }^{2 b}$, Shuang-hong $\mathrm{Yu}^{3 \mathrm{c}}$, Jiao Pang ${ }^{4 \mathrm{~d}}$, Shu-xia Ren ${ }^{5 \mathrm{e}}$, \\ jian-zhong $\mathrm{Xu}^{6 \mathrm{ff}}$
}

1, 2, 3,5,6 College of Chemistry and Environmental Science, Hebei University, No. 180 Wusi East Road, Baoding, Hebei Province, China (071002)

${ }^{4}$ College of Electronic and Informational Engineering Hebei University, No. 180 Wusi East Road, Baoding, Hebei Province, China (071002)

ajiaoyunhonghbu@163.com, b1049205335@qq.com, '841375121@qq.com, d965961776@qq.com,

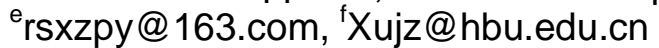

Key words: polypropylene, flame retardant, Iron-doped lanthanum stannate

Abstract: Iron-doped lanthanum stannate $\left(\mathrm{Fe}-\mathrm{La}_{2} \mathrm{Sn}_{2} \mathrm{O}_{7}\right.$, simplified as $\left.\mathrm{Fe}-\mathrm{La}\right)$ was prepared firstly and used as a synergistic agent of the intumescent flame retardant (IFR, the mixture of ammonium polyphosphate (APP) and pentaerythritol (PER) with mass ratio of 2:1) for polyphosphate (PP). The limiting oxygen index (LOI), UL-94 test, scanning electron microscopy (SEM), X-ray diffraction (XRD) and thermogravimetry-fourier transform infrared spectroscopy (FTIR) were used to evaluate the synergistic effects of Fe-La. It was found that a suitable amount (1.0\%) of Fe-La could not only improve the flame retardancy, but also can form a continuous, compact and intumescent char layer; over addition $(5.0 \%)$ of La-Fe into the PP/IFR system could reduce the flame retardancy and form a loose char.

\section{Introduction}

Phosphorous-containing, halogen-containing, silicon-containing, metal hydrate and oxide, nano-composite flame retardant formulations are the main five kinds of flame retardants of PP ${ }^{[1]}$. Phosphorous-containing intumescent flame retardants (IFRs) are found to be superior among the above flame retardants of PP ${ }^{[2-6]}$. The main components of an IFR system include an acid source, a carbon source, and a blowing agent. A typical IFR system is composed of ammonium polyphosphate (APP, acid source), pentaerythritol (PER, charring agent) and melamine (MEL, gas agent) ${ }^{[4-6]}$. APP can be used as not only an acid source, but also a blowing agent, caused by the formation of polyphosphoric acid and ammonia during its thermal degradation ${ }^{[7]}$. Therefore, APP/PER based IFR systems have been widely investigated, moreover, synergistic agents can be also added into the APP/PER system for improving flame retardancy ${ }^{[8-20]}$. Some authors have demonstrated that zeolites ${ }^{[8,9]}$, boron containing substances ${ }^{[10,11]}$, layered double hydroxide (LDH) ${ }^{[12-14]}$, as well as some metal oxides ${ }^{[7,15-16]}$ and metal salts ${ }^{[17]}$ can act as synergistic agents for effectively improving flame retardancy, and promoting the strength and stability of char layer.

Rare earth compounds such as $\mathrm{La}_{2} \mathrm{O}_{3}{ }^{[16]}, \mathrm{CeO}_{2}{ }^{[7]}$, Ce-doped titania nanotubes (Ce-NTs) ${ }^{[18]}$, and cerium phosphate $(\mathrm{CeP})^{[19-20]}$, have been used as synergistic agents of IFRs in PP and other polymer systems. So far there is no research on rare earth metal stannates as synergistic agents for PP/APP/PER system or other flame retardant polymers.

Therefore, the aims of the present work were to prepare a new kind of inorganic synergistic agent containing $\mathrm{La}$, Sn and $\mathrm{Fe}$ elements, iron doped lanthanum stannate $\left(\mathrm{Fe}-\mathrm{La}_{2} \mathrm{Sn}_{2} \mathrm{O}_{7}\right)$, investigate its flame retardant effect on PP/APP/PER system and find its best loading level. 


\section{Experimental section}

\section{Materials}

The materials used for the preparation of $\mathrm{Fe}-\mathrm{La}_{2} \mathrm{Sn}_{2} \mathrm{O}_{7}$ were as follows: $\mathrm{La}\left(\mathrm{NO}_{3}\right)_{3} \cdot 6 \mathrm{H}_{2} \mathrm{O}$ (Analytical grade, Tianjin Guangfu Fine Chemical Research Institute of China), $\mathrm{Fe}\left(\mathrm{NO}_{3}\right)_{3} \cdot 9 \mathrm{H}_{2} \mathrm{O}$, $\mathrm{NH}_{3} \cdot \mathrm{H}_{2} \mathrm{O}$ and $\mathrm{Na}_{2} \mathrm{SnO}_{3} \cdot 3 \mathrm{H}_{2} \mathrm{O}$ (Analytical grade, Tianjin Kemiou Chemical Co. of China).

The materials used to prepare the flame retardant PP samples were as follows: PP (S1003, Shanghai SECCO Petrochemical Company, China), ammonium polyphosphate (APP, $\left(\mathrm{NH}_{4} \mathrm{PO}_{3}\right)_{\mathrm{n}}$, Type II, n>1000, particle size about $10 \mu \mathrm{m}$, Shifang Taifeng New Flame Retardant Agent Limited Liability Company, China), pentaerythritol (PER, Tianjin Guangfu Fine Chemical Research Institute of China), antioxidant Irganox 1010 (pentaerythritol tetrakys 3-(3,5-ditert-butyl-4-hydroxyphenyl) propionate, $\mathrm{C}_{73} \mathrm{H}_{108} \mathrm{O}_{12}$, BASF, Germany) and titanate coupling agent NDZ-311 (bis (p, p-bis-ethylhexyl diphosphato) ethanediolato titanate, Analytical grade, Nanjing Shuguang Chemical Group Co., Ltd, China).

\section{Preparation of iron doped lanthanum stannate and flame retardant PP samples \\ Preparation of iron doped lanthanum stannate}

Equal molar concentration of $\mathrm{La}\left(\mathrm{NO}_{3}\right)_{3} \cdot 6 \mathrm{H}_{2} \mathrm{O}$ and $\mathrm{Fe}\left(\mathrm{NO}_{3}\right)_{3} \cdot 9 \mathrm{H}_{2} \mathrm{O}$ aqueous solution were firstly prepared, then a homogeneous solution of $\mathrm{Fe}\left(\mathrm{NO}_{3}\right)_{3} / \mathrm{La}\left(\mathrm{NO}_{3}\right)_{3}$ was prepared by mixing $5.00 \mathrm{ml}$ $\mathrm{Fe}\left(\mathrm{NO}_{3}\right)_{3}$ solution and $95.00 \mathrm{ml} \mathrm{La}\left(\mathrm{NO}_{3}\right)_{3}$ solution. A precipitate precursor was obtained by adding moderate amount of $\mathrm{NH}_{3} \cdot \mathrm{H}_{2} \mathrm{O}$ into the upper $\mathrm{Fe}\left(\mathrm{NO}_{3}\right)_{3} / \mathrm{La}\left(\mathrm{NO}_{3}\right)_{3}$ solution under rapid mechanical stirring, aging, filtration, washing and drying. The precipitate precursor was calcined several hours at moderate temperature in a muffle furnace, and then got the target product-iron-doped lanthanum stannate $\left(\mathrm{Fe}-\mathrm{La}_{2} \mathrm{Sn}_{2} \mathrm{O}_{7}\right)$ which labeled as $\mathrm{Fe}-\mathrm{La}$.

\section{Preparation of flame retardant PP samples}

Table 1 shows the formulations and flame retardant properties of PP and flame retardant PP samples. IFR represents the mixture of APP and PER in a mass ratio of 2:1. IFR/Fe-La represents the mixture of IFR and Fe-La, where IFR and Fe-La are represented in the following ratios: 24.9:0.1, 24.5:0.5, 24:1, 23:2, 22:3, and 20:5. The total loading levels of IFR and IFR/Fe-La were all 25 mass \% of the total mass for the flame retardant PP composites. The dosage of antioxidant Irganox 1010 was 0.5 mass\% of PP polymer, and that of titanate coupling agent NDZ-311 was 1 mass $\%$ of IFR/Fe-La.

The various components of every flame retardant PP sample were uniformly mixed in a highspeed mixer, and then melt-blended on a twin-screw extruder (SHJ-20, Nanjing Giant Machinery Co., Ltd., China). The temperature range of the twin-screw extruder was set at $165-180{ }^{\circ} \mathrm{C}$. The tested flame retardant PP samples were obtained by injection molding using an injection molding machine (SZ-15, Wuhan Ruiming Plastic Machinery Co., Ltd., China) and the temperature was set at $180-200^{\circ} \mathrm{C}$.

\section{Measurements and characterization \\ Characterization of Fe-La}

$\mathrm{X}$-ray powder diffractometer (D8-ADVANCE, Bruker, Germany) with $\mathrm{Cu}-\mathrm{K} \alpha$ radiation at room temperature was employed to observe the crystal structure of $\mathrm{Fe}-\mathrm{La}$. The operating conditions of the X-ray source were set at a voltage of $40 \mathrm{kV}$ and a current of $40 \mathrm{~mA}$, with scans in the range of $2 \theta=10-90^{\circ}$.

The morphology and elemental composition of Fe-La were observed by a field-emission scanning electron microscope (FE-SEM) (JSM-7500F, Japan Electron Optics Laboratory Co., Ltd., Japan) coupled with an energy-dispersive X-ray spectrometer (EDS) (Noran System 7, American), and the sample was observed after sputtering with gold.

\section{Flame retardant tests of the PP samples}

The LOI value is the minimum amount of oxygen in an oxygen $\left(\mathrm{O}_{2}\right)$-nitrogen $\left(\mathrm{N}_{2}\right)$ mixture required to support the complete combustion of a vertically held sample that burns in the downward direction from the top. In this study, the LOI values were determined in accordance with ASTM 
D2863 by using a general model JF-3 LOI instrument (Nanjing Jiangning Analysis Instrument Factory, China). The size of the test specimens was $130 \mathrm{~mm} \times 6.0 \mathrm{~mm} \times 3.0 \mathrm{~mm}$ (length $\times$ width $\times$ thickness).

The UL-94 vertical burning test was performed on a CZF-3 vertical burning instrument (Jiangning Analysis Instrument Co., China) according to the UL-94 test standard. The size of the test specimens was $130 \mathrm{~mm} \times 13 \mathrm{~mm} \times 3 \mathrm{~mm}$ (length $\times$ width $\times$ thickness).

\section{Char residues study of the flame retardant PP samples}

PP/IFR, PP/IFR/Fe-La-1.0 and PP/IFR/Fe-La-5.0 were studied by UL-94 tests, and their char residues were investigated. The internal and external surfaces of the char residues were observed by an SEM. The possible compositions and functional groups of the char residues were evaluated by powder XRD and an FTIR spectrometer, respectively.

\section{Results and discussion}

\section{Structure and morphology of Fe-La}

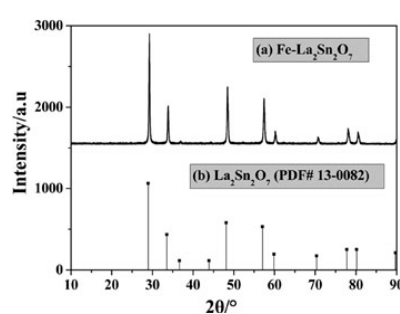

Fig. 1 XRD patterns and SEM photo of Fe -La

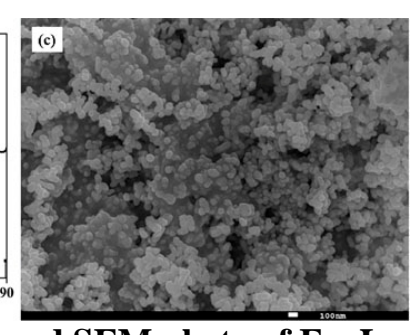

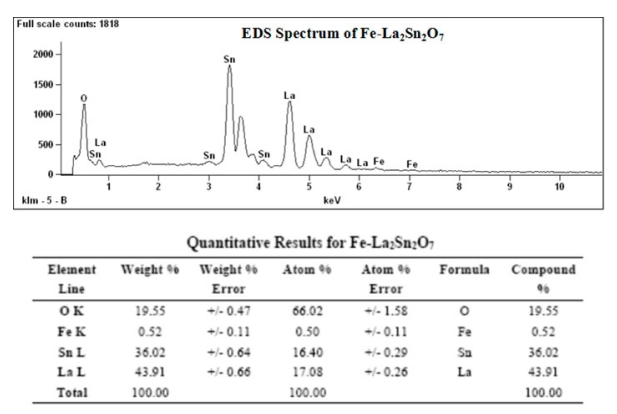

Fig. 2 EDS result of Fe -La

The crystal structure, morphology and element compositions of Fe-La were characterized by XRD, SEM and EDS methods, the results are shown in Figs. 1 and 2, respectively.

The positions of XRD peaks in Fig.1 (a) are consistent with those of $\mathrm{La}_{2} \mathrm{Sn}_{2} \mathrm{O}_{7}$ standard card (PDF \# 13-0082, Fig.1 (b)), suggesting that the crystal structure of Fe-La is the same as those of $\mathrm{La}_{2} \mathrm{Sn}_{2} \mathrm{O}_{7}$ (PDF \# 13-0082). As shown in Fig. 1 (c), Fe-La particles are irregular spheres or stripes, with particle sizes of approximately $20-50 \mathrm{~nm}$. Fig. 2 shows that that the mass percent of $\mathrm{O}, \mathrm{Fe}, \mathrm{Sn}$, and $\mathrm{La}$ elements in $\mathrm{Fe}-\mathrm{La}$ is $19.55 \%, 0.52 \%, 36.02 \%$, and $43.91 \%$, respectively.

3.2 Flame retardant properties of PP/IFR/Fe-La composites

Table 1 Formulations of PP samples

\begin{tabular}{cccccc}
\hline \multirow{2}{*}{ sample } & \multicolumn{3}{c}{ Formulation (wt.\%) } & \multicolumn{2}{c}{ Flame Retardancy } \\
\cline { 2 - 6 } & PP & IFR & Fe-La & LOI (\%) & UL-94 \\
\hline PP & 100 & 0 & 0 & 18.0 & No Rating \\
PP/IFR & 75.0 & 25.0 & 0 & 27.3 & V-1 \\
PP/IFR/Fe-La-0.1 & 75.0 & 24.9 & 0.1 & 28.0 & V-0 \\
PP/IFR/Fe-La-0.5 & 75.0 & 24.5 & 0.5 & 29.5 & V-0 \\
PP/IFR/Fe-La-1.0 & 75.0 & 24.0 & 1.0 & 31.0 & V-0 \\
PP/IFR/Fe-La-2.0 & 75.0 & 23.0 & 2.0 & 30.9 & V-0 \\
PP/IFR/Fe-La-3.0 & 75.0 & 22.0 & 3.0 & 30.8 & No Rating \\
PP/IFR/Fe-La-5.0 & 75.0 & 20.0 & 5.0 & 27.3 & No Rating \\
\hline
\end{tabular}

Compared with the PP sample, as shown in Table 1, the LOI values of flame retardant PP samples increased by 9.3-13 units and their UL-94 ratings changed with the variation of the Fe-La loading. As compared with those of the PP/IFR sample, the LOI values and UL-94 ratings of PP/IFR/Fe-La samples increased initially, was maintained constant, and finally decreased. 
PP/IFR/Fe-La-1.0 sample exhibited the highest LOI value (31.0\%) and UL-94 rating (V-0), whereas the PP/IFR/ Fe-La-5.0 sample exhibited the lowest LOI value (27.3\%) and UL-94 rating (no rating). These results indicated that there is an optimum weight ratio of Fe-La/IFR (1:24) at which an obvious synergistic effect exits between Fe-La and IFR; a higher weight ratio of 5:20 $\mathrm{Fe}-\mathrm{La} / \mathrm{IFR}$ results in the loss of the synergistic effect between Fe-La and IFR.

\section{Char residues study of the flame retardant PP samples}

The char residues of PP/IFR, PP/IFR/Fe-La-1.0 and PP/IFR/Fe-La-5.0 after their UL-94 tests were tested by SEM, FTIR and XRD tests, and their results are shown in Figs. 3 and 4.

\section{Morphology of the char residues}
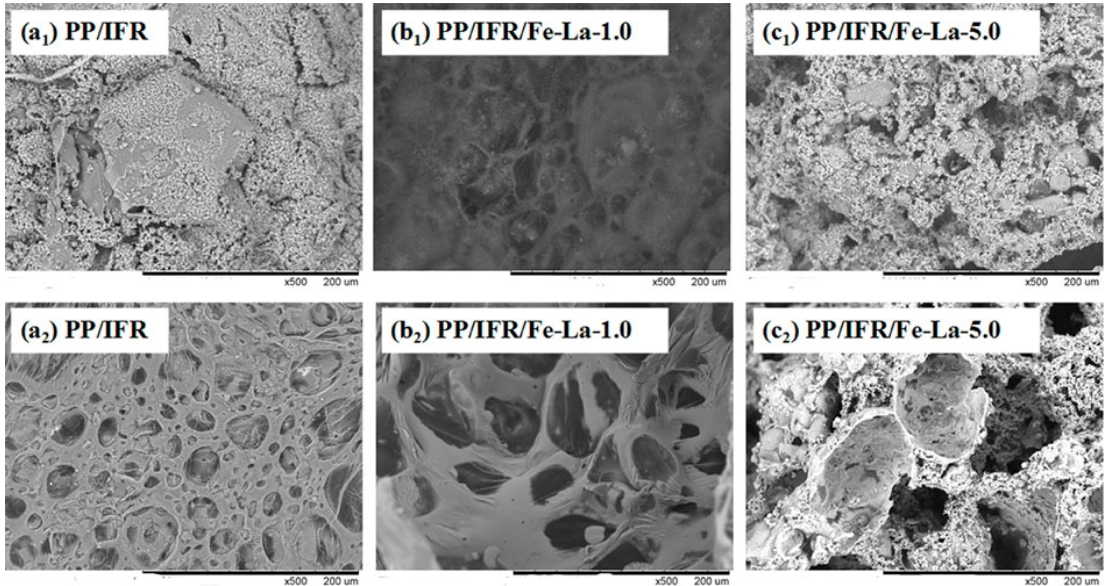

Fig. 3 SEM photos of the external and internal char surfaces of PP/IFR $\left(a_{1}, a_{2}\right)$, PP/IFR/ Fe-La-1.0 $\left(b_{1}, b_{2}\right)$ and PP/IFR/ Fe-La-5.0 $\left(c_{1}, c_{2}\right)$

Fig.3 shows the SEM images of the external and internal char surfaces of PP/IFR, PP/IFR/Fe-La-1.0, and PP/IFR/Fe-La-5.0. Both the external char surfaces of PP/IFR (Fig.3 (a $\left.a_{1}\right)$ ) and of PP/IFR/Fe-La-5.0 (Fig.3 $\left(\mathrm{c}_{1}\right)$ ) were composed of several loosely packed small solid particles, and the packing of the small particles in Fig.3 $\left(\mathrm{c}_{1}\right)$ was significantly loose as compared to that inFig.3 $\left(\mathrm{a}_{1}\right)$. However, the external char surface of PP/IFR/Fe-La-1.0 (Fig.3 $\left(\mathrm{b}_{1}\right)$ ) exhibited a compact porous surface without solid particles. Both the internal char surfaces of PP/IFR (Fig.3 $\left.\left(a_{2}\right)\right)$ and of PP/IFR/Fe-La-1.0 (Fig.3 $\left(\mathrm{b}_{2}\right)$ ) exhibited a continuous, rugged, compact and porous char layer with several closed pores, and the pore size inFig. $3\left(\mathrm{a}_{2}\right)$ was significantly greater than that inFig.3( $\left.b_{2}\right)$. However, the internal char surface of PP/IFR/Fe-La-5.0 (Fig.3 $\left(c_{2}\right)$ ) exhibited a more loose char layer, which was composed of several loosely packed small solid particles packed loosely and several large-sized enclosed looser pores.

The above description indicated that the char of PP/IFR/Fe-La-1.0 was the most compact, followed by that of PP/IFR, and finally, that of PP/IFR/Fe-La-5.0; this result is consistent with the order of their flame retardant properties. This result indicated that the suitable addition of $\mathrm{Fe}-\mathrm{La}$ into the PP/IFR system could form a continuous, internal, and external compact intumescent char layer; however, with the extra addition of Fe-La into the PP/IFR system, the closed pores could possibly break, thereby generating small solid particles in the inside and outside of the char. Hence, PP/IFR/Fe-La-1.0 and PP/IFR/Fe-La-5.0 exhibited the best and worst flame retardant properties, separately.

\section{FTIR analysis of the char residues}

As shown in Fig.4 (a), the FTIR spectrum of the char residue of PP/IFR only exhibited absorption peaks at 3452,2362 , and $1617 \mathrm{~cm}^{-1}$; while FTIR spectra of the char residue of PP/IFR/Fe-La-1.0 and PP/IFR/Fe-La-5.0 only exhibited peaks at 1406 and $1271 \mathrm{~cm}^{-1}$, respectively; however, FTIR spectra of the char residues of PP PP/IFR/Fe-La-1.0, PP-IFR, and PP/IFR/Fe-La-5.0 exhibited peaks at 2923 and $2859 \mathrm{~cm}^{-1}$; moreover, their intensities in the three samples decreased successively. 
The absorption peak at $3452 \mathrm{~cm}^{-1}$ was possibly attributed to three groups. First, the peak at $3452 \mathrm{~cm}^{-1}$ could be attributed to the stretching vibration of an intermolecularly associated hydroxyl group ( $v$ O-H 3550-3450 $\mathrm{cm}^{-1}$ ), which suggests that PER does not entirely participate in the combustion, and some PER molecules form dimers or multimers by intermolecular association. Second, the peaks at 3452 and $1617 \mathrm{~cm}^{-1}$ could be assigned to the stretching vibration and deformation vibration of the $\mathrm{O}-\mathrm{H}$ bond in crystal water $\left(v \mathrm{O}-\mathrm{H} 3600-3000 \mathrm{~cm}^{-1}, \delta \mathrm{O}-\mathrm{H} 1670-1600\right.$ $\mathrm{cm}^{-1}$ ), respectively, which suggest that $\mathrm{H}_{2} \mathrm{O}$, as one of the combustion products, remains in the char residue. Third, the peaks at 3452 and $1617 \mathrm{~cm}^{-1}$ could be attributed to the stretching vibration and deformation vibration of the N-H bond $\left(v \mathrm{~N}-\mathrm{H} 3509-3300 \mathrm{~cm}^{-1}, \delta \mathrm{N}-\mathrm{H} 1650-1550 \mathrm{~cm}^{-1}\right)$, which indicated that the $\mathrm{NH}_{4}{ }^{+}$of APP did not completely decompose into $\mathrm{NH}_{3}$ and it possibly reacts with the O-H of PER, resulting in the dehydration of water or formation of hydrogen bonds.

The peaks at 2955,2923 and $2859 \mathrm{~cm}^{-1}$ could be attributed to the stretching vibration of saturated $\mathrm{C}-\mathrm{H}$ bond of $-\mathrm{CH}_{3}\left(v \mathrm{C}-\mathrm{H} 2960 \pm 5,2870 \pm 10 \mathrm{~cm}^{-1}\right)$ and $-\mathrm{CH}_{2^{-}}(v \mathrm{C}-\mathrm{H} 2930 \pm 5,2850 \pm 10$ $\mathrm{cm}^{-1}$ ) groups; the peak observed at $1463 \mathrm{~cm}^{-1}$ is attributed to the deformation vibration of the $-\mathrm{CH}_{2}-$ and $-\mathrm{CH}_{3}$ groups $\left(v \mathrm{C}-\mathrm{H} 1460 \pm 10 \mathrm{~cm}^{-1}\right)$. This result implied that saturated alkanes exist in the char residue. The peaks at 2362 and $1002 \mathrm{~cm}^{-1}$ are attributed to the stretching and deformation vibration of the P-H bond of dialkyl phosphine oxide $\left(\mathrm{HR}_{2} \mathrm{P}=\mathrm{O}, v \mathrm{P}-\mathrm{H} 2380-2294 \mathrm{~cm}^{-1}, \delta \mathrm{P}-\mathrm{H} 1015-897\right.$ $\mathrm{cm}^{-1}$ ), respectively. The peak at $1002 \mathrm{~cm}^{-1}$ is also attributed to the stretching vibration of the $\mathrm{P}-\mathrm{O}$ bond of P-O-R $\left(v \mathrm{P}-\mathrm{O} 1050-990 \mathrm{~cm}^{-1}\right)$. The peak at $1271 \mathrm{~cm}^{-1}$ is attributed to the stretching vibration of the $\mathrm{P}=\mathrm{O}$ bond of $\mathrm{HR}_{2} \mathrm{P}=\mathrm{O}$ or $\mathrm{PO}_{3}{ }^{3-}\left(v \mathrm{P}=\mathrm{O} 1350-1250 \mathrm{~cm}^{-1}\right)$. The peak at $1406 \mathrm{~cm}^{-1}$ is attributed to the stretching vibration of $\mathrm{NO}_{3}{ }^{-}$in organic nitrates $\left(\mathrm{V} \mathrm{NO}_{3}{ }^{-} 1410-1340 \mathrm{~cm}^{-1}\right)$.

In other words, as shown in Fig.4 (a), the possible main components of the char residue of PP/IFR were crystal water, saturated alkanes, $-\mathrm{NH}_{2-}$, and $\mathrm{HR}_{2} \mathrm{P}=\mathrm{O}$ or $\mathrm{PO}_{3}{ }^{3-}$, while those of $\mathrm{PP} / \mathrm{IFR} / \mathrm{Fe}-\mathrm{La}-1.0$ were saturated alkanes, $\mathrm{HR}_{2} \mathrm{P}=\mathrm{O}$, or $\mathrm{PO}_{3}{ }^{3-}$, and organic nitrates; moreover, the main components of $\mathrm{PP} / \mathrm{IFR} / \mathrm{Fe}-\mathrm{La}-5.0$ were saturated alkanes, $\mathrm{HR}_{2} \mathrm{P}=\mathrm{O}$, or $\mathrm{PO}_{3}{ }^{3-}$. This result revealed that a suitable addition of Fe-La into the PP/IFR system would promote the formation of saturated alkanes and the reaction of APP and PER.
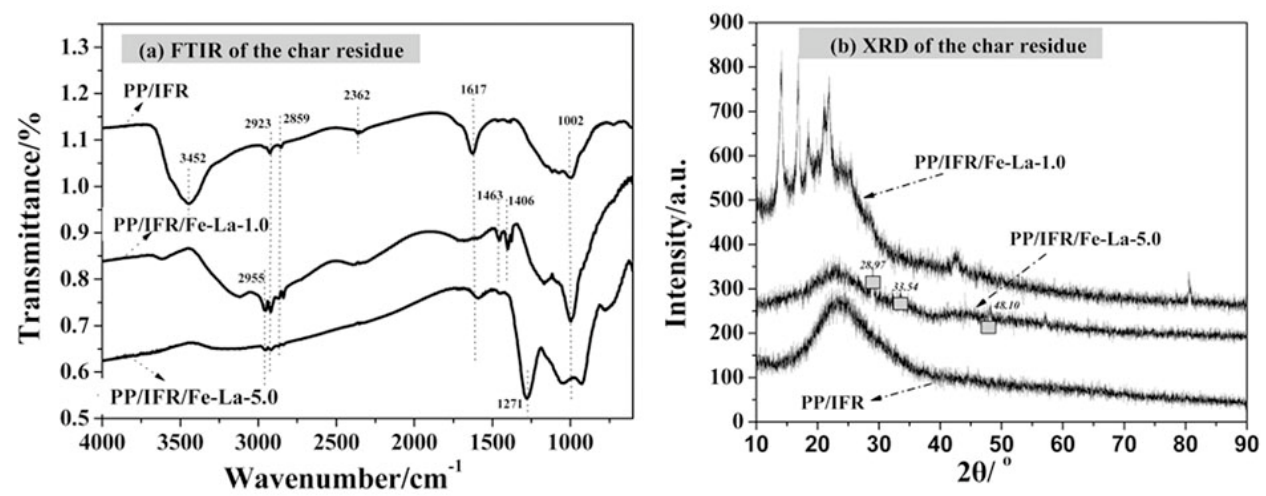

Fig. 4 FTIR (a) and XRD (b) of the char residues for PP/IFR, PP/IFR/ Fe-La-1.0

\section{and PP/IFR/ Fe-La-5.0}

\section{XRD analysis for the char residue}

Fig. 4 (b) shows the XRD patterns of the char residues of PP/IFR, PP/IFR/Fe-La-1.0 and $\mathrm{PP} / \mathrm{IFR} / \mathrm{Fe}-\mathrm{La}-5.0$, which showed much difference.

One wide diffraction peak was observed in the XRD of the char residue of PP/IFR, but it was difficult to ascertain the group or compound it corresponded to, which indicated that crystal compounds do not exist in the char residue of PP/IFR. Several sharp diffraction peaks were observed for the char residue of PP/IFR/Fe-La-1.0, which indicated that crystal inorganic compounds are present in this char residue. The peaks at 14.23 and $21.25^{\circ}$ may be attributed to the two strongest characteristic diffraction peaks (020) and (220) of ammonium hydrogen oxalate hydrate $\left(\mathrm{C}_{2} \mathrm{H}_{5} \mathrm{NO}_{4} \cdot 0.5 \mathrm{H}_{2} \mathrm{O}\right.$, PDF\# 39-1405); the peaks at $13.29,19.08$, and $21.20^{\circ}$ may be attributed to the three strongest characteristic diffraction peaks (002), (201), and (211) of fullerite $\left(\mathrm{C}_{70}\right.$, PDF\# 
50-1364), respectively. One wide diffraction peak and several weak sharp diffraction peaks were observed for the char residue of PP/IFR/Fe-La-5.0. The wide diffraction peak was similar with that for the char residue of PP/IFR. The peaks at $28.97,33.54$ and $48.10^{\circ}$ may be attributed to the characteristic diffraction peaks (222), (400), and (440) of $\mathrm{La}_{2} \mathrm{Sn}_{2} \mathrm{O}_{7}$ (PDF\# 13-0082), respectively; the peaks observed at $23.60,24.50,29.05,44.37,47.67,51.63$, and $64.58^{\circ}$ may be attributed to the characteristic diffraction peaks of hydrogen phosphate $\left(\mathrm{HPO}_{3}, \mathrm{PDF} \#\right.$ 05-0464). This result revealed that Fe-La possibly reacts completely with PP and IFR in the PP/IFR/Fe-La-1.0 system during combustion, with no reaction observed for the PP/IFR/Fe-La-5.0 system, which indicated that an optimum of $\mathrm{Fe}-\mathrm{La}$ concentration is beneficial for a synergistic effect.

\section{Conclusions}

(1) Iron-doped lanthanum stannate (Fe-La) with irregular spheres or stripes, with a particle size of 20-50 nm, was successfully prepared, and the loading of iron in Fe-La was $0.52 \mathrm{wt} \%$.

(2) Fe-La was used as a synergistic agent for the conventional intumescent flame retardant (IFR), which is a mixture of ammonium polyphosphate (APP) and pentaerythritol (PER) in a mass ratio of 2:1, for PP. When the loading level of Fe-La were $1.0 \%$ and $5.0 \%$, the flame retardant PP containing $25 \%$ IFR/Fe-La showed the best and worst flame retardant properties, respectively. Compared with PP/IFR, the changes of PP/IFR/Fe-La-1.0 were as follows: LOI increased 3.7 units, UL 94 test from V-1 to V-0 rating.

(3) The SEM images of the char residues indicated that the external and internal char surfaces of PP/IFR/Fe-La-1.0 were the most compact. The FTIR and XRD analyses of the char residue indicated that crystal water, saturated alkanes, $-\mathrm{NH}_{2-}$ and $\mathrm{HR}_{2} \mathrm{P}=\mathrm{O}$ or $\mathrm{PO}_{3}{ }^{3-}$ were the main components of the char from PP/IFR; an Fe-La loading of $1 \mathrm{wt} \%$ into the PP/IFR system was appropriate, which promoted the production of $\mathrm{C}_{2} \mathrm{H}_{5} \mathrm{NO}_{4} \cdot 0.5 \mathrm{H}_{2} \mathrm{O}, \mathrm{C} 70$, and organic nitrates in the solid phase for the char residue of PP/IFR/Fe-La-1.0; while an Fe-La loading of $5 \mathrm{wt} \%$ into the $\mathrm{PP} / \mathrm{IFR}$ system was excessive, and saturated alkanes, $\mathrm{HR}_{2} \mathrm{P}=\mathrm{O}, \mathrm{H}_{3} \mathrm{PO}_{3}$, and excessive $\mathrm{Fe}-\mathrm{La}$ were the solid compositions from the PP/IFR/Fe-La-5.0 char residue.

\section{Acknowledgements}

This work was financial support by the Hebei Province Science and Technology Project (13211402D), the Hebei Province Natural Science Foundation (B2014201101) and Hebei Province Postdoctoral Preferred Funded Project (2011005001).

\section{References}

[1] S. Zhang and A. R. Horrocks. Prog. Polym. Sci. Vol. 28 (2003), 28, p.1517.

[2] G. Fontaine, S. Bourbigot and S. Duquesne. Polym. Degrad. Stab. Vol. 93 (2008), p. 68.

[3] D. Enescu, A. Frache, M. Lavaselli, O. Monticelli and F. Marino. Polym. Degrad. Stab. Vol. 98 (2013), p. 297.

[4] M.L. Bras, S. Bourbigot, C. Delporte, C. Siat and Y.L. Tallec. Fire. Mater. Vol. 20 (1996), p.191.

[5] P. Lv, Z. Z. Wang, K. L. Hu and W. C.Fan. Polym. Degrad. Stab. Vol. 90 (2005), p.523.

[6] G.X. Li, G.Z. Liang, T. S. He, Q.L.Yang and X.F. Song. Polym. Degrad. Stab. Vol. 92 (2007), p. 569.

[7] J. Li and G.S. Liu. Polym. Degrad. Stab. Vol. 97 (2012), p. 2562.

[8] H. Demir, E. Arkıs, D. Balköse and S. Ülkü. Polym. Degrad. Stab. Vol. 89 (2005), p. 478.

[9] P. Wei, P.K. Jiang, Z.D. Han and J. Q. Wang. J. Fire. Sci. Vol. 23 (2005), p. 173.

[10] M. Dogan and E. Bayraml. Polym. Advan. Technol. Vol. 22 (2011), 1628.

[11] M. Dogan, A.Yilmaz and E. Bayramli. Polym. Degrad. Stab.Vol. 95 (2010), p. 2584.

[12] Z.Q. Shen, L.Chen, L. Lin, C. Liang, J. Zhao and Y.Z.Wang. Ind. Eng. Chem. Res. Vol.52 
(2013), p.8454.

[13] M. Zhang, P. Ding and B.J. Qu. Polym. Compos. Vol. 30 (2009), p.1000.

[14] M. Zhang, P. Ding, B.J. Qu and A. G. Guan. J. Mater. Process. Tech. Vol. 208 (2008), p. 342.

[15] M.Z. Dong, X.Y. Gu and S. Zhang. Ind. Eng. Chem. Res. Vol. 53 (2014), p.8062.

[16] C. M. Feng, Y. Zhang, S.W. Liu, Z.G. Chi and J. R. Xu. Polym. Degrad. Stab. Vol.97 (2012), p.707.

[17] X.Q. Su, Y.W. Yi, J. Tao and H.Q. Qi. Polym. Degrad. Stab. Vol. 97 (2012), p.2128.

[18] Y. Wu, Y.C. Kan, L. Song and Y. Hu. Polym. Advan. Technol. Vol. 23 (2012), p.1612.

[19] Z.H. Qiao, Q.L.Tai, L. Song, Y. Hu, P. Lv, G. X. Jie, W. Huang, Y. Fu and D. Q. Zhang. Polym. Advan. Technol. Vol. 22 (2011), p.2602.

[20] Z.H. Qiao, W. Yang, L. Song, Y. Hu, F.Q. Kong, J. Li, H.Z.Yan and W. Huang. Plast. Rubber. Compos. Vol. 40 (2011), p.413. 